\title{
Vacina como agente de imunização contra o HPV
}

\author{
Vaccines as an agent for immunization against HPV
}

Geisa Picksius Zardo ${ }^{1}$

Flávia Peixoto Farah ${ }^{1}$

Fernanda Gabriela Mendes ${ }^{1}$

Camila Ament Giuliani dos Santos Franco ${ }^{1}$

Giseli Vieira Machado Molina ${ }^{1}$

Gislaine Nochetti de Melo ${ }^{1}$

Solena Ziemer Kusma ${ }^{1}$

\footnotetext{
${ }^{1}$ Reitoria, Pontifícia

Universidade Católica

do Paraná. R. Imaculada

Conceição, Prado Velho.

80.215-901 Curitiba PR

Brasil.

geisapzardo@yahoo.com.br
}

\begin{abstract}
Considered a highly prevalent infection throughout the world, the human papillomavirus $(H P V)$ is a DNA virus that infects the genital mucosa and has high carcinogenic potential, being related to an increased risk of lower genital tract lesions, such as cervical cancer. This cancer is responsible for the deaths of about 231,000 women per year worldwide, which means that HPV is a major problem for public health. Knowing that the most effective and cost-effective way to control an infectious disease is the development of vaccines, two prophylactic vaccines have been developed and approved in Brazil, one of which is bivalent and the other is tetravalent. This review of the literature seeks to present the characteristics of the $H P V$ virus, types of vaccines available on the market, their indications and contraindications, their adverse effects, their effectiveness, their geometric mean titer (GMT) and their cost-effectiveness.
\end{abstract}

Key words Human papillomavirus, HPV vaccination, Public health
Resumo Considerada uma infecção de alta prevalência em todo o mundo, o papiloma vírus humano (HPV) é um DNA vírus que infecta a mucosa genital e possui grande potencial oncogênico, sendo relacionado ao risco aumentado de lesões do trato genital inferior, como o câncer cervical. Este câncer é responsável pela morte de cerca de 231 mil mulheres por ano no mundo, o que torna o HPV um grande problema para a saúde pública. Sabendo que a maneira mais eficaz e com melhor custo-benefício para controlar uma doença infecciosa é o desenvolvimento de vacinas, duas profiláticas foram desenvolvidas e aprovadas no Brasil, uma bivalente e outra quadrivalente. Essa revisão de literatura se propõe a apresentar as características do vírus $H P V$, os tipos de vacinas presentes no mercado, suas indicações e contraindicações, seus efeitos adversos, sua eficácia, seus títulos de anticorpos (GMT) e seu custo-efetividade.

Palavras-chave Papiloma vírus humano, Vacina HPV, Saúde pública 


\section{Introdução}

A infecção pelo papiloma vírus humano (HPV) é considerada atualmente a doença sexualmente transmissível com maior prevalência em todo o mundo ${ }^{1}$ O HPV está associado ao câncer cervical, um importante problema de saúde pública, que depois do câncer de mama, é um dos principais responsáveis pelas mortes do sexo feminino².

De acordo com dados da Organização Mundial da Saúde (OMS), uma em cada dez pessoas estão infectadas pelo HPV sendo detectados 500 mil novos casos de câncer cervical por ano. Aproximadamente $70 \%$ destes novos casos são observados em países subdesenvolvidos ou em desenvolvimento, sendo que cerca de 231 mil mulheres acabarão evoluindo para morte em decorrência de câncer cervical invasivo ${ }^{2-4}$. Mulheres acima de 50 anos apresentam grandes chances de portar o vírus, e dessa forma possibilitar o desenvolvimento de uma neoplasia relacionada ao HPV. Somado a isso, dados mostram que após os 56 anos, as mulheres apresentam maior predisposição para desenvolver lesões de alto risco (NIC 3), quando comparadas às mais jovens $\mathrm{s}^{5-7}$.

Além do câncer cervical, as verrugas genitais e as lesões pré-cancerosas do trato anogenital masculino e feminino também estão associados ao HPV, bem como os cânceres de cabeça e pescoço. Cerca de 32 milhões de casos novos de verrugas genitais são descritos ao ano mundialmente, no Brasil esses números chegam em torno de 1,9 milhões de casos relatados ${ }^{2,8}$. As demais neoplasias ligadas ao HPV, como a de vagina, vulva e ânus, também têm seu risco aumentado com a idade em mulheres previamente infectadas pelo vírus, principalmente se a mulher já possuir um histórico de lesão de alto grau (NIC 3) em colo de útero ${ }^{7}$.

A população masculina é a principal responsável pela transmissão da infecção ao sexo feminino, que ocorre de forma sexual. Isso ocorre porque, diferente de outras Doenças Sexualmente Transmissíveis (DST), o HPV é transmitido mais facilmente do homem para a mulher do que da mulher para o homem. Além disso, os homens também são atingidos por cerca de 10.000 casos de carcinomas relacionados ao HPV (pênis, ânus, laringe, orofaringe e cavidade oral). Em algumas regiões específicas do Brasil (Nordeste, por exemplo), a incidência de câncer anal e peniano é a maior do mundo ${ }^{2,8}$.

No Brasil, menos de $15 \%$ da população feminina está envolvida em algum programa de prevenção do câncer de colo de útero, o que pode explicar em parte a alta taxa de incidência dessa patologia no país ${ }^{4}$. Sabe-se que a vacinação é um método eficaz e de relevante custo-benefício para se combater uma doença de etiologia infecciosa ${ }^{5}$. Assim, em 2006, a Food and Drug Administration (FDA), aprovou a vacina quadrivalente como agente imunizador contra o HPV 9 . Nesse mesmo ano a Agência Nacional de Vigilância Sanitária do Brasil (Anvisa) regulamentou a comercialização dessa vacina².

O objetivo desta pesquisa é apresentar uma revisão da literatura da vacina como agente de imunização contra o papiloma vírus humano (HPV) como contribuição para formulação de políticas públicas na área de prevenção da doença em questão.

\section{Métodos}

O desenvolvimento desta revisão de literatura foi realizado por meio de busca em bases de dados eletrônicas, tais como: Bireme, Cochrane, Lilacs, Scielo, PubMed e portal da CAPES. Considerando os períodos de janeiro de 2006 a dezembro de 2012, incluindo os idiomas português e inglês. Os descritores utilizados para a busca das pesquisas foram HPV, papiloma vírus humano, infecções pelo HPV, vacina do HPV, vacina do HPV em grávidas e custo-efetividade da vacina do HPV.

Para a seleção dos artigos, foram utilizados os seguintes critérios de inclusão: resultados de pesquisa de acordo com a relevância relacionada ao título e aos objetivos da revisão, baseados na leitura dos seus respectivos resumos, restringindo-se ao uso das vacinas bivalente e quadrivalente. Realizou-se uma leitura crítica de cada artigo selecionado e em seguida foram realizadas comparações das informações de cada um deles.

Para análise foram selecionados 27 artigos, sendo 15 provenientes de países da América do Norte e Europa e 12 nacionais. Também foram considerados artigos não extraídos das bases citadas, mas pertinentes ao objetivo da revisão porque atendem a um dos critérios de inclusão acima citados: Junior ${ }^{10}$; Parellada e Campaner ${ }^{11}$; e Fedrizzi ${ }^{12}$.

A apresentação e discussão dos resultados encontrados são feitas sob sete perspectivas analíticas: as características do vírus HPV, os tipos de vacinas presentes no mercado, suas indicações e contraindicações, seus efeitos adversos, sua eficácia, seus títulos de anticorpos (GMT) e seu custo-efetividade. 


\section{Revisão da literatura}

\section{HPV}

O HPV é um vírus de DNA, com aproximadamente 8.000 pares de base, que tem como característica ser epiteliotrófico. O genoma do HPV é dividido em 3 regiões: Early (E), Long Control Region (LCR) ou Upstream Regulatory Region (URR) e Late (L). A região Early é assim denominada porque expressa precocemente as suas proteínas no ciclo viral, sendo as proteínas E6 e E7 as mais importantes. O grau de expressão de E6 e E7 está diretamente relacionado ao grau de lesão cervical. Em lesões de baixo grau o DNA do HPV é encontrado de forma epissomal, enquanto que em lesões de alto grau o DNA HPV se integra ao DNA da célula ${ }^{13}$.

São descritos hoje aproximadamente 130 genótipos de HPV, dos quais 40 infectam a mucosa genital, classificados como alto ou baixo risco em relação ao seu potencial oncogenético ${ }^{13,14}$. Os 12 tipos de HPV considerados carcinogênicos através de evidências em estudos são os HPV 16, 18, $31,33,35,39,45,51,52,56,58$ e $59^{7}$. Os tipos 16 e 18 são responsáveis juntos por cerca de $70 \%$ de todos os casos biopsiados de pacientes com câncer cervical, 50\% das lesões pré-cancerosas consideradas de alto risco e $25 \%$ das lesões de baixo risco $^{1,3-5,15}$.

A evolução da infecção pelo HPV no organismo humano é caracterizada na grande maioria dos casos como autolimitada e ocorrendo sua eliminação espontânea em aproximadamente dois anos, sem causar lesões e sintomas, pois sabe-se que somente a infecção pelo vírus não é suficiente para desenvolver o carcinoma ${ }^{7,14,16}$. Entretanto, sua persistência no organismo está intimamente relacionada ao risco aumentado de lesões do trato genital inferior, incluindo o câncer ${ }^{1,7}$. Entre a infecção pelo vírus e o desenvolvimento de lesões pré-malignas ou malignas existe um período de latência, sugerindo que existam outros fatores que poderiam atuar como cofatores na carcinogênese cervical, entre eles estão: iniciação sexual precoce, multiplicidade de parceiros sexuais, paridade, predisposição genética, status imunológico, baixa ingestão de vitaminas, tabagismo, uso de contraceptivos orais, nível socioeconômico e coinfecções por Chlamydia trachomatis e HIV $\mathrm{HI}^{1,3,5,7,8,14,16}$.

Estudos mostraram que a história natural da infecção por HPV no epitélio cervical não pode ser detectada a não ser que esta esteja em processo de replicação viral. Isso acontece de forma mais pronunciada em mulheres pós-púberes, o que explicaria o fato de a maior parte das infecções por HPV serem diagnosticadas nessa faixa etária ${ }^{3,5,7}$.

\section{Vacina}

Em países desenvolvidos, a utilização de programas de prevenção de câncer cervical baseados em exames de colpocitologia oncótica ou Papanicolaou realizados regularmente e tratamento adequado de lesões pré-cancerosas, mostram-se eficazes em reduzir a incidência de doenças e sua mortalidade desde a década de 1970. Entretanto, esta abordagem é cara e pode ser difícil de implementar e manter em locais de recursos escassos ${ }^{17}$. Outros estudos demostram ainda que os testes de screening usando o DNA viral do HPV testado de forma isolada teria uma confiabilidade comparável ou até mesmo superior ao uso do exame de Papanicolaou como screening. O exame de DNA do HPV apresentou um alto valor preditivo negativo, o que permite que este exame seja realizado em intervalos de 3 a 5 anos, e que se estas medidas fossem implementadas, a eficiência da triagem poderia aumentar com um mínimo impacto sobre o risco de câncer ${ }^{16}$.

Visando o combate da disseminação do vírus e o controle das lesões HPV induzidas, foram desenvolvidos dois tipos de vacinas contra o HPV, a profilática e a terapêutica, porém esta última ainda se mostra com baixa eficácia ${ }^{1}$.

A vacina profilática estimula a resposta humoral, baseada no contato com "partículas semelhantes ao vírus" ou virus-like particles (VLP), que se caracterizam com morfologia semelhante ao vírus sem, contudo, conter o DNA viral, responsável pelos danos da infecção por esse agente. O capsídeo dos papilomavírus contém duas proteínas, a L1 e a L2. A expressão dessas proteínas gera os VLP, que são a principal fonte de antígenos empregadas em ensaios clínicos para o desenvolvimento de vacinas profiláticas. Esses anticorpos induzidos pela vacina são liberados na mucosa genital, impedindo o quadro infeccioso precocemente $e^{1,4,14}$.

Já a vacina terapêutica é produzida a partir de outras proteínas que têm sido propostas como antígenos vacinais, principalmente E6 e E7. Estas proteínas estão envolvidas no descontrole da proliferação e transformação celulares, induzindo a resposta celular do sistema imune, sensibilizando células imunocompetentes para combater à infecção viral ${ }^{1,4}$.

No Brasil foram aprovadas duas vacinas profiláticas contra o HPV, sendo elas a bivalen- 
te da GlaxoSmithKline (2009) e a quadrivalente da Merck Sharp e Dohme (2006). Essas vacinas contêm a proteína L1 do capsídeo viral e são produzidas por tecnologia recombinante com o objetivo de obter partículas análogas virais dos dois tipos mais comuns presentes nas neoplasias cervicais, o HPV16 e o HPV18, responsáveis por $70 \%$ dos casos desse tipo de neoplasia ${ }^{2,3,79,15}$.

Além do tipo 16 e 18, a vacina quadrivalente também previne infecções pelos tipos 6 e 11, responsáveis por $90 \%$ das verrugas na região genital e lesões em colo uterino de baixo risco. Ela ainda mostrou-se eficiente contra metade das infecções pelo HPV 31. A vacina bivalente apresentou eficácia adicional contra quase todas as infecções por HPV 31, 33 e 45, 4,5,7,9.

Supõe-se que ambas as vacinas para o HPV previnem além do câncer cervical, outros tipos de cânceres relacionados ao HPV, com eficácia moderada para alta ${ }^{8}$. É estimado que se houver vacinação completa da população, os casos de câncer cervical podem ser reduzidos em dois ter$\operatorname{ços}^{9}$. Deve-se levar em conta que o Brasil possui uma boa experiência em cobertura vacinal com a realização de programas nacionais, mostrando com isso sua capacidade de realizar uma vacinação eficiente contra os tipos de HPV oncogênicos na população alvo $^{18}$.

Uma forma de desenvolver uma ampla cobertura é realizar uma vacina multivalente, fato já visto em outras vacinas licenciadas. Dessa forma, tem sido sugerida a formulação de uma vacina contendo os oito tipos de HPV mais comuns, com potencial de atingir uma proteção maior que $90 \%$ contra o câncer cervical. Porém, para a sua realização seria necessário aumentar a complexidade da preparação e o custo da vacina ${ }^{14}$.

A Tabela 1 elucida as características da vacina anti-HPV quadrivalente e bivalente, abordando aspectos de sua composição, posologia, indicação, imunogenicidade, segurança e proteção cruzada.

\section{Indicações e contraindicações para o uso da vacina}

Embora a infecção pelo HPV possa ocorrer em mulheres sexualmente ativas em qualquer idade, sabe-se que seu pico de incidência ocorre logo após o início da vida sexual, antes dos 25 anos de idade. Apesar da taxa diminuir a partir

Tabela 1. Características da vacinas anti-HPV.

\begin{tabular}{|c|c|c|}
\hline Característica & Quadrivalente & Bivalente \\
\hline \multicolumn{3}{|l|}{ Composição } \\
\hline Tipo & VLP L1 HPV 6,11,16,18 & VLP L1 HPV 16,18 \\
\hline Concentração & $20 \mu \mathrm{g}$ HPV 6 e $18 / 40 \mu \mathrm{g}$ HPV 11 e 16 & $20 \mu \mathrm{g}$ HPV 16 e 18 \\
\hline Adjuvante & $\begin{array}{l}225 \mu \mathrm{g} \text { sulfato de hidroxifosfato amorfo } \\
\text { de alumínio (AAHS) }\end{array}$ & $\begin{array}{l}500 \mu \mathrm{g} \text { hidróxido de alumínio }+50 \mu \mathrm{g} \\
\text { de monofosforil lipídio-a (ASO4) }\end{array}$ \\
\hline Tecnologia recombinante & $\begin{array}{l}\text { Expressão em levedura (Saccharomyces } \\
\text { cerevisae) }\end{array}$ & $\begin{array}{l}\text { Expressão com baculovírus em células } \\
\text { de inseto (Trichoplusnia ni) }\end{array}$ \\
\hline Nome comercial & $\begin{array}{l}\text { Vacina Quadrivalente Recombinante } \\
\text { contra Papilomavírus Humano }{ }^{\circledR} \text { (Brasil) }\end{array}$ & $\begin{array}{l}\text { Vacina contra HPV oncogênico (16 e } \\
18 \text { Recombinante com ASO4) }{ }^{\circledR} \text { (Brasil) }\end{array}$ \\
\hline Posologia & 0,5 mL IM 0, 2 e 6 meses & $0,5 \mathrm{~mL}$ IM 0,1 e 6 meses \\
\hline Indicação (Brasil) & Homens e mulheres de 9 a 26 anos & Mulheres de 10 a 25 anos \\
\hline \multicolumn{3}{|l|}{ Imunogenicidade } \\
\hline Soroconversão & $100 \%$ para os quatro tipos de HPV & $100 \%$ para os dois tipos de HPV \\
\hline Resposta amnéstica & Evidente e robusta & Evidente e robusta \\
\hline \multicolumn{3}{|l|}{ Segurança } \\
\hline Geral & Geralmente segura e bem tolerada & Geralmente segura e bem tolerada \\
\hline Gravidez & $\begin{array}{l}\text { Categoria B / não associada a } \\
\text { malformação ou má evolução obstétrica }\end{array}$ & Não há dados \\
\hline Lactação & Segura e bem tolerada & Segura e bem tolerada \\
\hline \multicolumn{3}{|l|}{ Proteção cruzada } \\
\hline & Eficácia (NIC 2/3 ou AIS) & Eficácia (infecção persistente) \\
\hline HPV 31/45 & $62 \%(95 \%$ IC $10-85)$ & \\
\hline HPV 31/33/45/52/58 & $43 \%(95 \%$ IC 07-66) & $60 \%(97,9 \%$ IC $28-79)$ \\
\hline HPV 31/33/35/39/45/51/52/56/58/59 & $38 \%(95 \%$ IC $06-60)$ & $41 \%(97,9 \%$ IC $20-56)$ \\
\hline
\end{tabular}

Fonte: Giraldo et al. ${ }^{2}$ 
desta idade, mulheres com idade superior a 25 anos também estão susceptíveis a infecção pelo vírus. É possível cogitar inclusive um segundo pico para a infecção entre a quarta e quinta décadas de vida. Não há consenso sobre a causa dessas novas infecções, especulam-se várias teorias: reativação viral, enfraquecimento da imunidade ou outro mecanismo $0^{5-7,16,19}$.

Por se tratar de uma infecção de transmissão vertical, o ideal seria a vacinação profilática em idade anterior à primeira relação sexual. Isto implicaria em vacinar crianças e adolescentes de ambos os sexos. Contudo, ainda são necessários estudos de acompanhamento da imunogenicidade e de custos-efetividade para a incorporação em toda a rede de atenção primáriaa ${ }^{3,4,14}$. As vacinas atualmente disponíveis estão indicadas para mulheres de 10 a 25 anos, a bivalente, e de 9 a 26 anos, a quadrivalente, sendo esta última também autorizada para meninos ${ }^{2,19}$.

O FDA orienta que as duas vacinas disponíveis contra o HPV sejam aplicadas por via intramuscular em 3 doses, sendo a quadrivalente aplicada nos meses 0,2 e 6 e a bivalente aplicada nos meses 0,1 e 6, respeitando um intervalo mínimo de 4 semanas entre a primeira e a segunda dose, 12 semanas entre a segunda e a terceira dose e 24 semanas entre a primeira e a terceira dose ${ }^{7,9}$.

Apesar de preconizar avaliações das imunizações realizadas há mais de 10 anos para a verificação da eficácia, segurança e o tempo de validade da vacina profilática contra o HPV, os resultados encontrados até o momento sugerem não haver necessidade de reforço vacinal, minimizando maiores custos da necessidade de aplicação de doses de reforço ${ }^{2}$. Porém, pelo pouco tempo da vacina, não se sabe ainda por quanto tempo essa imunização perdurará e se serão necessárias doses de reforço $0^{6}$.

As vacinas podem ser aplicadas tanto em pacientes imunodeprimidos quanto em mulheres que estão amamentando, pois é composta de partículas semelhantes ao vírus, e não propriamente pelo vírus ${ }^{6}$.

Em grávidas a vacina do HPV é classificada como categoria B pela FDA, não sendo recomendada durante a gestação. Em estudo realizado por Dana et al. ${ }^{20}$, com 787 grávidas em estudo prospectivo e 76 grávidas em estudo retrospectivo, que engravidaram inadvertidamente antes ou logo após o uso da vacina quadrivalente, foram analisados a quantidade de nascidos vivos, a morte fetal, os abortos espontâneos e os defeitos congênitos. Após dois anos de acompanhamen- to não foi possível estabelecer um relação entre a exposição à vacina e problemas fetais na gravidez, entretanto a quantidade de exposições não foi suficiente para enfatizar o baixo risco da vacina nessas condições.

Outra fonte de dados acerca desse assunto é uma análise realizada por Garland et al. ${ }^{21}$ de 5 ensaios clínicos randomizados de fase III que incluíram 3620 mulheres que engravidaram durante ou logo após a aplicação das doses da vacinas quadrivalente ou placebo. Nesta análise não foram encontradas diferenças significativas entre os fetos nascidos vivos, morte fetal ou aborto espontâneo. Foram encontrados 40 casos de malformação neonatal entre as grávidas que receberam a vacina, não diferindo do encontrado entre a população geral ${ }^{10,21}$.

Assim, apesar dos estudos realizados não mostrarem aumento de defeitos congênitos, até o momento não existem estudos e dados suficientes para recomendar a vacina em mulheres grávidas. O mais indicado seria esperar o término da gestação para aplicar a vacina. Caso ocorra a gestação durante o período da vacinação, esta deve ser interrompida e completada após o parto, sem diminuição de sua resposta imunológica ${ }^{6,10,22}$.

\section{Segurança - efeitos adversos}

Antes de ser aprovada, em 2006, pela FDA, a vacina quadrivalente passou por inúmeros ensaios clínicos com mais de 21 mil mulheres com idade entre 9 e 26 anos. Os ensaios clínicos de fase I demonstram a eficácia da administração das vacinas profiláticas contra HPV tipo 11 e tipo 16 por via subcutânea ou intramuscular, não havendo nenhum tipo de reação adversa durante estes estudos. As doses variaram entre 10 e 100 microgramas de VLP purificadas, manipuladas puras ou combinadas com hidróxido de alumínio. Foram realizadas duas a três doses de reforço com intervalos de 4 a 6 semanas ${ }^{4,9}$.

Em 2008 foram distribuídas 23 milhões de doses da vacina nos Estados Unidos, sendo que menos de $1 \%$ das doses distribuídas apresentaram efeitos adversos relatados. Dentre esses efeitos adversos $94 \%$ foram considerados como não graves, incluindo cefaleia, náuseas e vômitos; $6 \%$ foram considerados graves, incluindo Síndrome de Guillain-Barré, choque anafilático, dano ao sistema nervoso central e morte. Em nenhuma das mortes relatadas foi evidenciada relação com a vacina? 


\section{Eficácia}

A vacina bivalente mostrou boa eficácia em pacientes com NIC 2 causados por HPV 16 ou 18 em mulheres previamente soropositivas, porém DNA negativo no momento de início do esquema vacinal. Esta vacina também demonstrou ser eficaz contra as verrugas genitais causadas pelo HPV 6 e 11 através de reações cruzadas ${ }^{7}$.

Com relação à eficácia da vacina quadrivalente (vírus 6, 11, 16 e 18), foram analisados dois ensaios clínicos de fase III: o Females United to Unilaterally Reduce Endo/Ectocervical Disease I (FUTURE I) e o Females United to Unilaterally Reduce Endo/Ectocervical Disease II (FUTURE II). Ambos são ensaios clínicos multicêntricos, randomizados, duplo cegos e controlados por placebo, utilizando mulheres não grávidas na faixa etária de 15 a $26 \operatorname{anos}^{1,9,15,23,24}$.

Em FUTURE I foram randomizadas 5455 mulheres, utilizando como critérios de inclusão ausência de história prévia de verruga genital ou citologia cervical anormal e um máximo de 4 parceiros sexuais durante a vida. As mulheres foram divididas em dois grupos, sendo que um grupo recebeu a vacina e o outro o placebo, e acompanhadas durante 3 anos após a vacinação ${ }^{9}$. Nesse estudo registrou-se $100 \%$ de eficácia da vacina, na análise por protocolo, para o desenvolvimento de lesões intraepiteliais de baixo grau, alto grau e adenocarcinoma. Quando avaliada a eficácia por intenção de tratar a taxa diminui para $62 \%$ (IC = 46-74) para lesões intraepiteliais de baixo grau, não se mostrando significativa nas lesões de alto grau e adenocarcinoma ${ }^{1,24}$.

Em relação aos subtipos dos vírus, a vacina quadrivalente revelou $100 \%$ de eficácia contra os vírus $6,11,16$ e 18, com o intervalo de confiança para o vírus 11 insignificante. Quando analisada por intenção de tratar a taxa diminui para $46 \%$ $(\mathrm{IC}=21-61)$ contra o vírus 16 e $76 \%(\mathrm{IC}=21$ 61) contra o vírus $18^{1,24}$.

Em FUTURE II, foram randomizadas 12167 mulheres, sem antecedentes de alterações citológicas e com um máximo de 4 parceiros sexuais. Observou-se a eficácia da vacina para aparecimento de lesões de alto grau de $100 \%$ para NIC II $($ IC $=86-100)$ e $97 \%$ para NIC III $($ IC $=79$ 100), não sendo significativos os valores pela análise por protocolo de adenocarcinoma. Quando avaliada por intenção de tratar a taxa de eficácia vai para $57 \%$ para NIC II (IC $=38-71)$, 42\% para NIC III (IC $=23-61)$ e $28 \%($ IC $<0-82)$ para adenocarcinoma. Nesse mesmo estudo foi avaliada a eficácia contra os vírus de alto risco (16 e 18), registrando 97\% ( $\mathrm{IC}=84-100)$ e $100 \%(\mathrm{IC}=$ 61-100), respectivamente. Por intenção de tratar registraram-se taxas de eficácia de $42 \%$ (IC $=22$ 86) para o vírus 16 e 79\% ( $\mathrm{IC}=49-93)$ para o vírus $18^{1,15,23}$.

As mulheres com infecção ausente para os 4 tipos de vírus presentes na vacina antes da vacinação se beneficiam plenamente da imunização, adquirindo proteção contra a doença causada pelos 4 tipos de HPV da vacina. Já as mulheres infectadas com um ou mais tipos presentes na vacina antes da vacinação se beneficiam parcialmente, imunizando-se apenas contra aqueles vírus que não contactuaram ${ }^{19}$.

Em uma pesquisa realizada por Giuliano et al. ${ }^{25}$, em 2007, que comparou seis estudos de fase II e III, constatou que a vacina profilática obteve eficácia de $100 \%$ contra neoplasia cervical intraepitelial ou adenocarcinoma in situ, causadas pelo HPV-16 e HPV-18 $8^{9,25}$.

O Quadro 1 apresenta de maneira resumida as características dos estudos FUTURE I e FUTURE II.

\section{Títulos de anticorpos}

Em ensaios clínicos de fase I concluídos até 2006, ocorreu um aumento da soropositividade aos antígenos virais, indicando a imunogenicidade da vacina ${ }^{4}$.

Ensaios clínicos de fase II mostram que as vacinas são diferentes quanto às respostas de anticorpos que induzem. A vacina bivalente induz a títulos altos e sustentados de anticorpos anti-HPV 16 e 18 durante cerca de 5 anos e meio, já a vacina quadrivalente mostra títulos altos de anticorpos no início contra o HPV18, que vão decaindo progressivamente após 3 anos $^{3}$.

Em estudo realizado em diferentes países (Colômbia, França, Alemanha, Filipinas, Espanha, Tailândia e Estados Unidos) entre junho de 2004 e abril de 2005, 3819 mulheres com idade entre 28 e 40 anos foram incluídas e randomizadas para receber vacina ou placebo. Destas, 3692 receberam 3 doses da vacina. Um terço dessas mulheres foram positivas para HPV 6, 11, 16 ou 18 no início do estudo, confirmados por sorologia ou teste de DNA. Entretanto, a maioria das mulheres foi negativa ou positiva para apenas 1 dos 4 tipos de HPV presentes na vacina ${ }^{19}$.

Constatou-se então que os títulos de anticorpos relacionados à vacina atingiram um pico máximo no $7^{\circ}$ mês, diminuindo até a estabilidade relativa entre 24 e 48 meses. Entre as mulheres previamente HPV-negativo as taxas 
Quadro 1. Características dos estudos FUTURE I e FUTURE II.

\begin{tabular}{|c|c|c|}
\hline & FUTURE I & FUTURE II \\
\hline Faixa etária dos participantes & $16-24$ & $15-26$ \\
\hline Número de parceiros sexuais & $\leq 4$ & $\leq 4$ \\
\hline Critérios de exclusão & $\begin{array}{l}\text { Gravidez, história prévia de papanicolau } \\
\text { anormal ou verrugas genitais }\end{array}$ & $\begin{array}{l}\text { Gravidez e história prévia de } \\
\text { papanicolau anormal }\end{array}$ \\
\hline Componentes da vacina & VLP contra o HPV 6, 11, 16 e 18 & VLP contra o HPV 6, 11, 16 e 18 \\
\hline Administração das doses & meses 0,2 e 6 & meses 0,2 e 6 \\
\hline Frequência do exame citológico & a cada 6 meses & a cada 12 meses \\
\hline Metas primárias & $\begin{array}{l}\text { Avaliar a incidência do HPV } 6,11,16 \text { e } \\
18 \text { associados a verrugas genitais, NIC } \\
1-3 \text {, NIV 1-3, NIVA 1-3, AIS e câncer } \\
\text { cervical, vulvar ou vaginal }\end{array}$ & $\begin{array}{l}\text { Avaliar a associação do HPV } 16 \text { e } 18 \\
\text { com o câncer cervical, NIC 2-3 e AIS }\end{array}$ \\
\hline $\begin{array}{l}\text { Eficácia por análise de protocolo } \\
\text { referente às lesões }\end{array}$ & $\begin{array}{l}100 \% \text { para o desenvolvimento de lesões } \\
\text { intraepiteliais de baixo grau, alto grau e } \\
\text { adenocarcinoma }\end{array}$ & $\begin{array}{l}100 \% \text { para NIC II e } 97 \% \text { para NIC } \\
\text { III, não sendo significativos os } \\
\text { valores para adenocarcinoma }\end{array}$ \\
\hline $\begin{array}{l}\text { Eficácia por intenção de tratar } \\
\text { referente às lesões }\end{array}$ & $\begin{array}{l}62 \% \text { para lesões intraepiteliais de baixo } \\
\text { grau, não se mostrando significativa nas } \\
\text { lesões de alto grau e adenocarcinoma }\end{array}$ & $\begin{array}{l}57 \% \text { para NIC II, } 42 \% \text { para NIC III } \\
\text { e } 28 \% \text { para adenocarcinoma }\end{array}$ \\
\hline $\begin{array}{l}\text { Eficácia por análise de protocolo } \\
\text { referente aos tipos virais }\end{array}$ & $100 \%$ contra os vírus $6,11,16$ e 18 & $\begin{array}{l}97 \% \text { contra o vírus } 16 \text { e } 100 \% \\
\text { contra o vírus } 18\end{array}$ \\
\hline $\begin{array}{l}\text { Eficácia por intenção de tratar } \\
\text { referente aos tipos virais }\end{array}$ & $\begin{array}{l}46 \% \text { contra o vírus } 16 \text { e } 76 \% \text { contra o } \\
\text { vírus } 18\end{array}$ & $\begin{array}{l}42 \% \text { contra o vírus } 16 \text { e } 79 \% \text { contra } \\
\text { o vírus } 18\end{array}$ \\
\hline
\end{tabular}

Fonte: Lu et al..$^{15}$; Future $\mathrm{II}^{23}$; Garland et al. ${ }^{24}$

de soroconversão no mês 7 foram 98,4\% para o HPV 6, 98,1\% para o HPV 11, 98,8\% para o HPV 16 e 97,3\% para o HPV 18. No $48^{\circ}$ mês, 91,5\%, 92\%, 97,4\%, e 47,9\% das mulheres imunizadas foram consideradas ainda soropositivas para HPV 6, 11, 16 e 18, respectivamente, conforme demonstra o Gráfico 1. Embora se observe que a soropositividade para o HPV 18 diminui mais rapidamente do que os outros tipos de HPV presentes na vacina, não foram relatados nenhum caso de doença ou infecção relacionada a esse tipo entre as mulheres vacinadas. Em relação às mulheres que eram soropositivas para algum dos vírus presentes na vacina antes da imunização, observou-se após a vacinação títulos de anticorpos mais elevados para esse tipo de HPV se comparadas as mulheres soronegativas ${ }^{19}$.

Giuliano et al. $^{25}$ analisaram as bases de dados de seis estudos de fase II e III, que envolviam
12343 pacientes, para determinar a existência de efeitos entre as características intrínsecas e reações imunológicas da vacina entre as pacientes participantes da pesquisa. No mês 7 os títulos de anticorpos (GMT) diminuíram em média $2 \%$ a $6 \%$ a medida que o tempo da vacinação aumentou, para os quatro tipos de vírus. Nenhum fator previu qual seria o decréscimo no mês 7 , pois cada tipo de HPV foi influenciado por características de cada base de dados dos trabalhos, como raça, região geográfica, índice de massa corporal, uso de contraceptivos e lactação ${ }^{9,25}$.

\section{Custo-efetividade}

A maneira mais consistente de se comprovar o custo-efetividade de uma determinada terapêutica é a análise direta de dados reais já existentes. A vacina contra o HPV pode ser analisada 


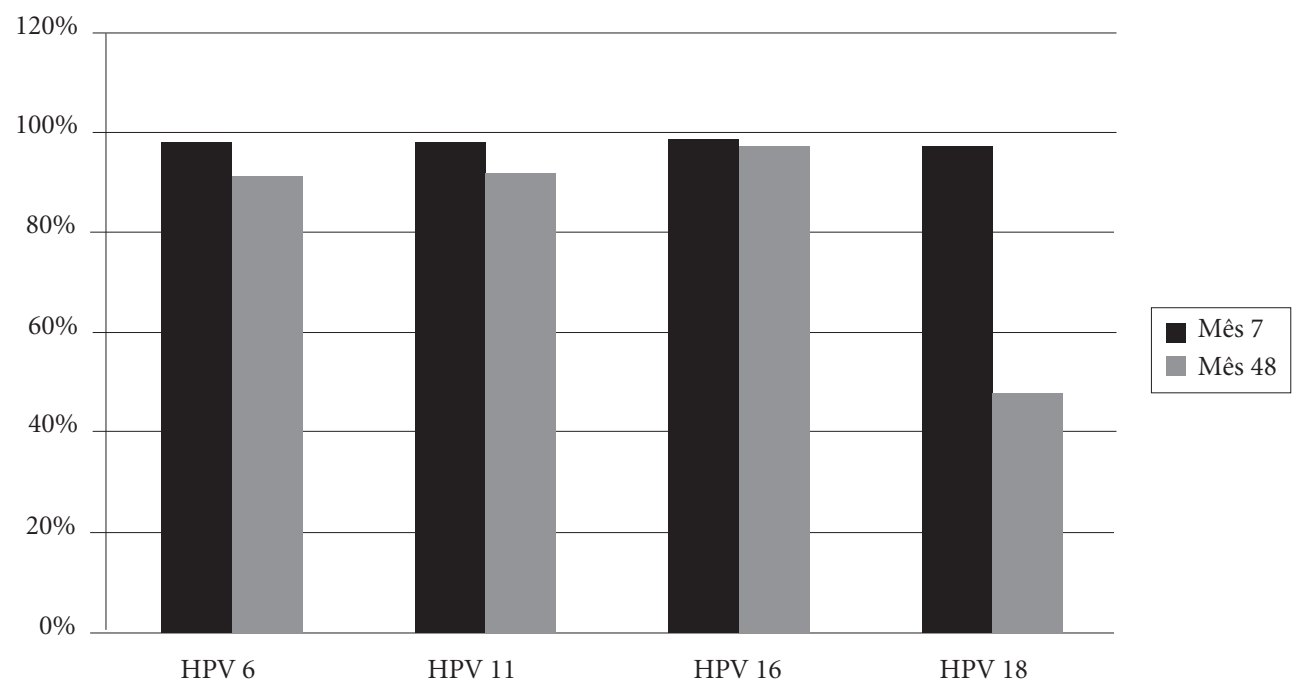

Gráfico 1. Taxas de soroconversão da vacina contra o HPV.

Fonte: Bragagnolo et al. ${ }^{19}$

desta forma, pois mais de 35 países já incluíram a vacina no calendário vacinal de imunização, entre os quais podemos citar Austrália, Canadá, México, Estados Unidos, Panamá, Bélgica, Portugal, Alemanha, Holanda, Dinamarca, Espanha, Suíça, Suécia, França e Reino Unido ${ }^{11}$.

Entre eles, a Austrália foi um dos primeiros países a implementar a vacina contra o HPV de forma gratuita para a população feminina. A imunização com a vacina quadrivalente começou a ser realizada a partir de abril de 2007 nas escolas para meninas de 12 a 18 anos e julho de 2007 em centros de saúde e clínicas para mulheres de 18 a 26 anos, sendo realizada até o final de 2009. A partir de 2010 a vacina passou a ser realizada apenas para meninas de 12 a 13 anos. $O$ custo foi estimado em 463 milhões de dólares australianos e mais de 100 milhões para sua implementação ${ }^{12}$.

Após 4 anos da introdução da vacina, notouse redução de $90 \%$ das taxas de verrugas genitais em mulheres e homens heterossexuais abaixo dos 21 anos, com menores taxas de redução na faixa etária de 21 a 29 anos. Acredita-se que a redução das taxas em homens ocorreu devido à chamada imunidade de rebanho, ou seja, mesmo que este grupo não tenha sido vacinado, eles se beneficiaram com a redução da circulação dos tipos de HPV que causam a verruga genital por meio da vacinação das mulheres. Não houve redução das verrugas genitais em homens e mulheres heterossexuais acima dos 30 anos e no grupo de homens homossexuais, sendo estes grupos não elegíveis para receber a vacina ${ }^{11,12}$.

Registrou-se também, uma diminuição na incidência de NIC 2, NIC 3 e adenocarcinoma in situ, na colpocitologia oncótica, em 47,5\% nas mulheres abaixo de 18 anos quando comparados dados de 2003-2007, antes da implementação da vacina, com dados de 2007-2009, de acordo com o Registro de Citologia Cervical de Victoria, um dos centros de registro deste exame na Austrália ${ }^{12}$.

\section{Considerações finais}

Atualmente são descritos 40 genótipos de HPV que infectam a mucosa genital, entre os quais 12 são considerados carcinogênicos. Em sua fase inicial de infecção, o vírus não causa danos ao organismo, não podendo ser detectado. Entretanto, sua persistência no organismo, aliada a outros fatores, está relacionada com lesões no trato genital inferior, incluindo o câncer.

Os programas de prevenção de câncer cervical podem ser eficazes em reduzir a incidência de doenças e sua mortalidade quando o diagnóstico é feito nos estágios iniciais da doença, porém estas medidas são de difícil implementação em locais com recursos escassos. Com isso, as vacinas 
profiláticas ganham espaço na luta contra o HPV, principalmente por terem sua eficácia comprovada nos países que já a implementaram em seu calendário vacinal, nos quais obteve-se redução das manifestações do vírus em até $90 \%$.

Dessa forma é comprovado com evidência científica que a aplicação da vacina, em homens e mulheres, contendo os quatro tipos virais mais importantes resultará na diminuição do índice de infectados e, consequentemente, na redução de gastos com tratamentos. De acordo com os estudos analisados, torna-se relevante o papel da vacinação em mulheres, devendo ser dada atenção especial àquelas sexualmente ativas com até
25 anos, pois estas possuem maior risco de adquirirem novas infecções por HPV.

O Sistema de Saúde do Brasil possui uma boa experiência em cobertura vacinal com a realização de programas nacionais, possibilitando uma promoção eficiente de vacinação contra os tipos de HPV oncogênicos na população alvo. Vale ressaltar a necessidade de que estudos voltados ao custo-efetividade da ação sejam realizados no contexto nacional.

Assim, a promoção de medidas profiláticas ao HPV cria grandes perspectivas na comunidade médica, além de trazer considerável benefício na qualidade de vida da população.

\section{Colaboradores}

GP Zardo, FP Farah, FG Mendes, SZ Kusma, GVM Molina, GN Melo e CAGS Franco participaram igualmente de todas as etapas de elaboração do artigo. 


\section{Referências}

1. Silva MJPM A, Gonçalves A, Katherine S, Giraldo PC, Pontes AC, Dantas GL, Silva RJO, Silva LGP. A eficácia da vacina profilática contra o HPV nas lesões HPV induzidas. Femina 2009;37(10):1-8.

2. Giraldo PC, Silva MJP, Fedrizzi EN, Gonçalves AKS, Amaral RLG, Junior JE, Figueiredo IV. Prevenção da infecção por HPV e lesões associadas com o uso de vacinas. DST - J bras Doenças Sex Transm 2008; 20(2):132140.

3. Rosa MI, Medeiros LR, Rosa DD, Bozzeti MC, Silva FR, Silva BR. Papilomavírus humano e neoplasia cervical. Cad Saude Publica 2009; 25(5):953-964.

4. Linhares AC, Villa LV. Vaccines against rotavirus and human papillomavirus (HPV). J Pediatr 2006; 82(3):25-34.

5. Castellsague $X$, Muñoz N, Pitisuttithum P, Ferris D, Monsonego J, Ault K, Luna J, Myers E, Mallary S, Bautista OM, Bryan J, Vuocolo S, Haupt RM, Saah A. End-of-study safety, immunogenicity, and efficacy of quadrivalent HPV (types 6,11,16,18) recombinant vaccine in adult women 24-45 years of age. $\mathrm{Br} \mathrm{J}$ Cancer 2011; 105(1):28-37.

6. Nadal SR, Manzione CR. Vacina Contra o Papilomavirus Humano . O Que é Preciso Saber? International Journal 2010; 30(2):237-240.

7. Harper DM, Vierthaler SL. Next Generation Cancer Protection: The Bivalent HPV Vaccine for Females. ISRN obstetrics and gynecology 2011(2011):1-20.

8. Natunen K, Lehtinen J, Namujju P, Sellors J, Lehtinen $M$. Aspects of prophylactic vaccination against cervical cancer and other human papillomavirus-related cancers in developing countries. Infect Dis Obstet Gynecol 2011; 1-10.

9. Pomfret TC, Gagnon JM, Gilchrist AT. Quadrivalent human papillomavirus (HPV) vaccine: a review of safety, efficacy, and pharmacoeconomics. Journal of clinical pharmacy and therapeutics 2011;36(1):1-9.

10. Junior GM. Vacina contra o papilomavírus humano: uso em gestantes e risco de malformações. Rev Bras Patol Trato Genit Infer 2012; 2(2):81-82.

11. Parellada C, Campaner AB. Vacinas contra o papilomavírus humano: aspectos atuais. Rev Bras Patol Trato Genit Infer 2012; 2(2):47-53.

12. Fedrizzi EN. Estudo comentado - Experiência australiana com a vacina quadrivalente anti-HPV. São Paulo: Merk; 2012.

13. Weiss TW, Rosenthal SL, Zimet GD. Attitudes toward HPV Vaccination among Women Aged 27 to 45. ISRN obstetrics and gynecology 2011;(2011):1-6.

14. Roden R, Wu TC. How will HPV vaccines affect cervical cancer? Nature Reviews Cancer 2006; 6(10):753763.

15. Lu B, Kumar A, Castellsagué X, Giuliano AR. Efficacy and safety of prophylactic vaccines against cervical HPV infection and diseases among women: a systematic review e meta-analysis. BMC infectious diseases 2011; 11(13):1-16.

16. Gravitt PE. The known unknowns of HPV natural history. The Journal of Clinical Investigation 2011; 121(12):4593-4599.
17. Guimarães MVMB, Michelin MA, Lucena AAS, Lodi CTC, Miranda MIL, Murta EFC, Melo VH. Resposta imune ao HPV e as neoplasias intra-epiteliais cervicais em mulheres infectadas e não infectadas pelo HIV: perfil de citocinas. Femina 2011; 39(5):275-280.

18. Borba PC, Teixeira J, Roteli-Martins CM, Carvalho NS, Naud PSV, Neves NA. O que falta na luta contra o câncer de colo uterino? Diagn Tratamento 2010; 15(4):198202.

19. Bragagnolo AL, Eli D, Haas P. Papiloma Vírus Humano (HPV). RBAC 2010; 42(2):91-96.

20. Dana A, Buchanan KM, Goss MA, Seminack MM, Shields KE, Korn S, Cunningham ML, Haupt RM. Pregnancy outcomes from the pregnancy registry of a human papillomavirus type 6/11/16/18 vaccine. Obstet gynecol 2009; 114(6):1170-1178.

21. Garland S, Ault K, Gall S, Paavonen J, Sings H, Ciprero K. Pregnancy and infant outcomes in the clinical trials of a human papillomavirus type 6/11/16/18 vaccine: a combined analysis of five randomized controlled trials. Obstet Gynecol 2009; 114(6):1179-1188.

22. Narducci A, Einarson A, Bozzo P. Human papillomavirus vaccine and pregnancy. Can Fam Physician 2012; 58(3):268-269.

23. Future II SG. Quadrivalent vaccine against Human Papillomavirus to prevent high-grade cervical lesions. $N$. Engl J Med 2007; 356(19):1915-1927.

24. Garland SM, Hernandez-Avila M, Wheeler CM, Perez G, Harper DM, Leodolter S, Tang GW, Ferris DG, Steben M, Bryan J, Taddeo FJ, Railkar R, Esser MT, Sings HL, Nelson M, Boslego J, Sattler C, Barr E, Koutsky LA; Females United to Unilaterally Reduce Endo/Ectocervical Disease (FUTURE) I Investigators. Quadrivalent vaccine against Human Papillomavirus to prevent anogenital diseases. N. Engl J Med 2007; 356(19):19281943.

25. Giuliano A, Lazcano-Ponce E, Villa L, Nolan T, Marchant C, Radley D, Golm G, McCarroll K, Yu J, Esser MT, Vuocolo SC, Barr E. Impact of baseline covariates on the immunogenicity of a quadrivalent (types $6,11,16$ and 18) human papillomavirus virus-like-particle vaccine. J Infect Dis 2007; 196(8):1153-1162.
Artigo apresentado em 20/03/2013

Aprovado em 12/04/2013

Versão final apresentada em 15/04/2013 